\title{
Gender and discipline: publication practices in Design
}

Teena Clerke, University of Technology, Sydney

\begin{abstract}
Design research and writing began to appear in scholarly journals over 30 years ago, coinciding in Australia with the transition of Design education into universities.

Concurrently, a significant increase in the number of women in what could be considered a male-dominated profession and emergent discipline actuated feminist-informed 'women and Design' writing. While this writing raised important questions about gender and Design, it is generally not cited in Design literatures that do not have a specifically feminist focus, and as this article will attest, publication and citation rates demonstrate the dominance of men in positions of influence in scholarly Design journals. This is particularly problematic for female Design academics and for the field in the current audit climate in universities, whereby state-funded research output is measured by citation analysis systems. Drawing on feminist and Foucauldian theorizations of power and knowledge, and supported by an empirical audit and analysis of gender distribution in publication in two scholarly Design journals, I argue first that scholarship as a form of social practice in new professional fields such as Design is complexly disciplined and problematically gendered. Second, I argue that further empirical research, and new and different kinds of feminist-informed writing that attend closely to issues of gender, is required to productively disrupt and reconceptualize Design scholarship as it is currently practiced.
\end{abstract} Comment [u1]: Please confirm the changes made to this sentence.

Comment [OU2R1]: Change accepted 


\section{Keywords:}

women

design

publication

practice

gender

feminism 


\section{Introduction}

Internationally, since the mid-1980s, there has been a significant increase in the number of women in Design and Design education (McQuiston 1988), while Design has emerged as a scholarly discipline. Yet scholarly Design literatures are notable for their absence of female authors and writing arising from women's interests and issues, and women remain under-represented in senior academic positions in Design, as in universities more generally (Tessens 2008).

As an emergent discipline, scholarly research in Design is relatively new. As with other immature disciplines arising from professional contexts, the word 'practice' as associated with Design is often used as a preface to signify that a particular activity or entity, such as 'practice-oriented research' or 'practice-led research', is research differentiated from that of other disciplines because of its origin in professional practice. Yet there is little theorization of 'practice', and a lack of clarity around the distinction between the activity or entity (research) and that from which it is differentiated ('non-practice-led' research?).

Further, confusion around the meaning of 'practice' in such terms often stems from the distinction made between 'research', as that which is done as a form of scholarship, and 'practice', as that which is done in a profession, in this case designing. In Design, as is the case in other emergent professional fields, academics are often experienced professionals who identify as Design 'practitioners', who perhaps continue to design, while teaching Design and also researching and writing about Design. For such academics, and particularly those new to research and writing, such a distinction between 'research' and 'practice' obfuscates how scholarship is practiced (in Design) and how this 
practice is regulated and disciplined. This makes it difficult for new scholars to identify and negotiate problematic social issues in such practices, for example that of gender.

In this article, I propose a conceptualization of Design scholarship as practice, to draw attention to and collapse the distinction between scholarship and profession so that the problematic operation of gender in the social practice into which new academics become acculturated and through which they are 'disciplined' can be addressed in new and productive ways. In this sense, the exploration of gender in scholarship practices in this discussion serves as an exemplar for other professional fields.

As a newcomer, Design writing for scholarly journals is subject to the same conditions and processes that regulate entry to and within scholarly journals in more established academic fields. To be accepted for submission, articles must conform to explicit specifications of format, font, size, margin, paragraph spacing, word length, referencing style, and so on. More importantly, to be accepted for publication, authors are required to both demonstrate their knowledge of the field through reference to key scholars and debates, and persuasively argue the contribution of their work to this knowledge, which is judged through peer review.

Through adherence to these practices and through publication, each new author is sanctioned by their 'peers' as 'one who knows', while their references reinforce the legitimacy of those cited as 'knowers'. Foucault refers to such citation protocols as ‘commentary', which operates to ‘discipline’ bodies and speech, and to regulate and manage social spaces such as journals. Informed by feminism, Threadgold (1997: 123) interprets 'commentary' as the 'ceaseless recitation of the same $[\ldots]$ which performs the 
relationship between primary and secondary texts' in these spaces. In other words, the disciplinary practices of scholarship reproduce the authority of those most often cited while inculcating new authors into practice. In this article, I engage these constructs to frame my analysis and discussion of the operation of gender in the bounded space of scholarly journals in Design.

I present two arguments. First, I argue that the disciplinary-formation and field-building practices in Design are gendered, and gendered in a multiplicity of ways. While this position is not new or even surprising, my intention is not to demonstrate women's marginalization or exclusion, but instead to map the gendered distribution of publication in two key scholarly journals by analysing and teasing apart the multiple layers of complexity to demonstrate how such journals come to be gendered spaces. This analysis offers a reflection on how the Design field is being constituted, and how women and men are being constituted in the field.

Second, I argue that this raises new questions and opens space for further study and different kinds of feminist-informed writing to make sense of how particular women and particular men, but most particularly women, are positioning themselves, and how this positioning is being practised in relation to decision-making about career-building through scholarly publication.

To support these arguments, I undertake a number of tasks. First, I outline a theoretical framing engaging with questions of practice and commentary, which will inform the analysis. Second, I explicate the contemporary conditions under which research in universities is measured, funded and published, using the Australian context as an 
example. Third, I analyse the results of an empirical audit of the publication histories of two key scholarly Design journals. Fourth, I critically review the 'women and Design' literatures to problematize the relations between feminism and Design writing. Finally, I reflect on the implications for women, men and Design. In reflecting, I suggest that rather than an 'ain't it awful' diatribe, what might be produced is a reconsideration of gendered publication practices in Design and, following Threadgold (1997: 29), 'an ethical rewriting which defines a distance between what is and what ought to be'.

\section{On 'practice', 'commentary' and 'discipline'}

As a way to structure my analysis later in this article, I wish to trouble the concept of 'practice' as commonly understood in professional practices such as Design, whereby attention is drawn to the noun before 'practice'. Hence, in discussions about 'Design practice', the focus is on the relations between Design and knowledge, rather than on practice and knowledge (Green 2009). As Green argues, what is discussed here is what is being practiced, the knowledge of how we practice, or 'how we think in the course of doing a practice' (Kemmis cited in Green 2009: 40). Yet the relations between practice and knowledge remain under-theorized. Green proposes a concept of the world as practice, whereby the professional world is theorized as a form of practicing the social. In this article, attention is directed to Design scholarship as practice, and as professional practice.

Professional practices, according to Green (2009: 43, 47, 48), consist of speech and bodies in orchestrated interactions, co-producing the social world. Here, the world is

Comment [j3]: Please check and confirm the provided page numbers are for the citation Green (2009).

Comment [OU4]: Page numbers are correct 
inherently dialogical; practice is 'always-already social'; and professional practice is complex, characteristically fuzzy, indeterminate, dynamic, and a form of invention as well as routinized behaviours. Individuals are 'carriers of practice' and agency is located Comment [u5]: Please confirm the change made to this sentence. in the practice (as a nexus of doings and sayings), rather than in the individual. This Comment [OU6]: Change accepted means that what people say and do is constituted in and by practice, and thus subjectivities, or the 'speaking positions' available to individuals, are also constituted in and by practice. Green argues that practices happen 'in excess of' (emphasis added) and prior to the subject, subjectivity and agency, which means that Design scholarship (as practice) exists before people can ‘be’ (positioned as) Design scholars.

Practice comprises action and activity, as a 'temporally unfolding and spatially dispersed nexus of doings and sayings’ (Schatzki cited in Green 2009: 47), and practice is 'polythetic', meaning that it is capable of managing complexity, and a multiplicity of confusions and contradictions (Robbins cited in Green 2009: 46),49).

In describing the world as practice, a consideration of the relations between practice and representation is required. Green asks, 'in what sense might we speak of knowing practice - of the knowingness in practice, as well as the activity of knowing itself, regarding practice?' What characterizes it? How can it best be described and understood, and what does it look like?

In this inquiry into and representation of the nexus of sayings and doings comprising Design scholarship, I explore the 'speaking positions' available to women and men, while capturing, rather than seeking to resolve, the complexity and contradiction in these practices. The analysis in this article is structured by Green's-Polkinghorne's summation 
of Bourdieu's (cited in Green 2009: 46) features of practice, as occurring in space and

time; guided by tacit understanding; and purposeful and strategic. To underpin the ‘commentary’.

For Threadgold (1997: 24, 26, 27), Foucault proposes a change in the order of discourse and ways of seeing, from a Marxist hierarchical order in which individuals are constrained from above and below, to a spatial organization of various forms of cellular grids (nodal networks). Here, space is transformed into a technology (practice) of discipline controlled by a political technology (practice) of the body. Discourses and bodies 'circulate' in space, regulated by discipline, which is an apparatus for the control of populations.

From this viewpoint, scholarly journals become bounded spaces of power and knowledge, constituted and organized by practices that produce speaking subjects, and also the field. In such spaces the 'microphysics of power' function by 'naming and classifying, distributing and positioning, belong[ing] to no individual but locat[ing] everyone'. Bodies and speech become disciplined by practice, controlled by 'the structured regularities of discourse [that] are related to the subject through desire $[\ldots]$ in the form of the power of knowing, and the will to know'.

As bounded spaces of power and knowledge, journals are regulated by certain textual practices, while the practices of positioning oneself within one of these journals produces the self, and also the field within a particular kind of space. In these journals, and particularly those that are highly ranked, positioning occurs through the activities of
Comment [j8]: Please check and confirm the provided page numbers are for the citation Green (2009)

Comment [j9]: Please check and confirm the provided year and page number is for the citation Threadgold (1997).

Comment [OU10]: Pages 24, 26 correct 
authoring and authentication. This involves ‘commentary' and peer review, in which the relationship between certain texts is played out repeatedly as cited authors continue to be cited, regulating and managing the bounded spaces of scholarly journals in ways that make them possible and also desirable to enter. Threadgold explains:

Authorship and its various historical and authenticating forms also works to control chance, as do the disciplines themselves, despite the fact that Foucault argues that disciplines are set up in opposition to the principles of commentary and authorship. Discipline is unauthored, anonymous. It is not owned by those it disciplines, and it remains a discipline only as long as it can continue to produce - 'ad infinitum fresh propositions'. (Foucault 1970/1971: 223) (cited in Threadgold 1997: 23)

It is precisely how these practices operate to control chance, and to discipline bodies and discipline speech, on which I focus in my analysis. I do not claim that women are consciously excluded from disciplinary spaces, but instead that this might occur unconsciously, and as gender is a pre-conscious space (the default order is normatively masculine), it is often not visible. With the aim of making gender visible in the bounded 'space’ of two scholarly Design journals, the question is, how do these regulatory practices constitute subjectivities, and also constitute the field? And, how might this analysis provide opportunities for further study and new feminist-informed writing that might productively disrupt and reconceptualize such 'spaces'? As background to this 
exploration, I explicate the contemporary 'space' of research funding and publication in universities using the context in Australia as an example.

\section{On publication: peer-review and citation practices}

Writing about Design began to appear internationally in scholarly art and architecture journals more than three decades ago, coinciding with a significant increase in the number of women in Design practice and education (McQuiston 1988). As founding publications for an emergent professional practice discipline, these early articles are notable for the absence of female authors, and the paucity of issues relevant to women. Here, I do not discount the 'women and Design' (Attfield 2003: 77) literatures that problematize the relations between Design and women; however, beyond the small network of feminist Design writers and writers with a specific interest in women in Design, this work is not generally cited in broader Design literatures. I provide a brief critique of these 'women and Design' literatures later in this article to support my second argument.

Since then, Design writing has proliferated, as have scholarly Design journals, yet women's representation in these journals and subsequent citation networks remains problematically disproportional to their representation in practice and in academic positions in universities (Tessens 2008). 
In the current audit climate in universities of 'publish or perish', government funding for research is determined by research output. In Australia, as is the case internationally, output is measured through a state-regulated citation analysis system

${ }^{1}$ that maps and calculates the distribution, quality and impact of a range of publication categories and competitive research grants. While books and book chapters are ranked highest in these systems, peer-reviewed articles for scholarly journals and articles published in refereed conference proceedings are currently rated at the same level, although in Australia this is expected to change (Australian Research Council 2008a, 2008b: 5, 14, 21). In a value-for-effort ratio, this makes writing for journals attractive to scholars concerned with profile-building and field-building.

Comment [j11]: Please specify is it Australian Research Council (2008a) or Australian Research Council (2008b) here as per reference list.

Comment [OU12]: Confirmed, 2008a

Journals are also competitively ranked according to 'authoritative status', the highest level being A*. The Australian Research Council (2008a: 21) describe such journals, described as 'one of the best sources of references in the field or subfield', in which 'most of the work is important [... (it will really shape the field) and where researchers boast about getting accepted'. Until recently in Australia, journals representing newer fields of scholarship such as Design attracted a lower ranking than the more established Comment [u13]: The meaning of this sentence is unclear. Please check.

Comment [OU14]: Clarified sentence

et al. 2008) conducted to inform the Australian Government's Excellence in Research for Australia (ERA) trial:

The research points allocated to design faculties or design schools in Australian universities depend on the ranking of the journal in which an article appears. Research income will follow these points, as will 
the credibility that researchers have when they apply for grant

funding. (Friedman et al. 2008: 4)

Using the journals in the audit that follows as an example, Design Studies and Design

Issues are ranked as $\mathrm{C}$ journals in the current Australian journal ranking system, yet in the survey they rank as A* journals. In national audit systems such as this, these

discrepancies disadvantage new writers, and writers in emergent professional disciplines such as graphic design, as they seek to publish in lower-ranked Design journals, or compete for space in higher-ranked journals in more established disciplines that privilege traditional (non-Design and masculine) knowledges. They also function as a barrier to the dissemination of newer knowledges and marginalized voices, such as those of women. A feminist reading of these processes of discipline-formation suggests that women are doubly disadvantaged, first by their omission from the makings and concerns of the field as represented in scholarly literatures, and second by the relational networks of power that operate in peer-review and citation practices that reproduce the gendered conditions under which Design is written. Although the Australian Research Council (2008a:zoosb: 3, 13, 14) ranking of Design Studies and Design Issues as C journals suggests that the discussion about 'esteem' that follows is not directly relevant to the audit and analysis of gender distribution of publication in these journals in this article, these rankings are likely to change as a result of recent high-level submissions in dialogue with the Australian government's upcoming ERA trial. ${ }^{2}$

At the institutional level, academic levels and 'esteem' in universities are quantified, the indicators of which include 'editorial roles at A* and A ranked journals_and]; contribution to a prestigious work of reference'. Interestingly for the analysis that

Comment [j15]: Please check and confirm the provided page numbers are for the citation Australian Research Council (2008).

Comment [j16]: Please specify is it Australian Research Council (2008a) or Australian Research Council (2008b) here as per reference list.
Comment [u17]: Please confirm whether an 'and' can be inserted before 'contribution' to separate these two points, as the meaning of the sentence is unclear. 
follows, 'editorial role includes the roles of editor, associate editor, and/or member of an editorial board', while a prestigious work of reference 'is one of the best in its field or subfield [which] would be characterised by a refereeing process and high scholarly standards, equivalent to an $\mathrm{A}$ */A ranked journal'. Such indicators constitute an obvious gender bias, as men hold the majority of senior academic positions in universities (Tessens 2008) and editorial positions in A* journals, as my audit will attest.

While I acknowledge that journalistic writing is important to professional disciplines such as Design, in this article I focus on scholarly writing; and while books attract the highest research output ranking, I focus on the peer-review and citation practices of scholarly journals, as this most productively highlights the gendered social organization of power and knowledge. Similarly, while I identify as a graphic designer, the discussion is relevant to other Design fields.

To reiterate, my central arguments are that the interactions between women and scholarly Design writing remain complexly and problematically gendered, and that an exploration of the technologies that operate in Design scholarship as practice calls for further study and different kinds of writing that have the potential to productively disrupt and reconstitute these gendered relations of power and knowledge, particularly in the bounded space of scholarly journals.

To provide empirical evidence that supports these arguments, I mapped and analysed the gender distribution of publication in two scholarly Design journals in conjunction with a feminist reading of the ERA Indicator Descriptors (Australian Research Council 2008az008b) of research measurement and funding in the Australian context. By feminist

Comment [j18]: Please specify is it Australian Research Council (2008a) or Australian Research Council (2008b) here as per reference list.

Comment [OU19]: Confirmed 2008a 
reading, I mean to make visible (in order to disrupt) Design scholarship as gendered practice.

\section{On gender distribution in publication: an audit}

I have argued that the disciplinary knowledge and theory-making processes of the

scholarly Design journal genre are problematically gendered. In other words, I argue that the conditions under which women write are different to those of men in a multiplicity of ways. To support this argument, there is a need to take account of and make explicit what is written and published, where it is published and by whom, and, more importantly, who and what is missing from this account.

To establish an empirical basis for the argument and building on a map of the gendered distribution of power and prestige in Design published elsewhere (Bower et al. 2009), I conducted a survey of two scholarly Design journals, Design Studies and Design Issues. As previously discussed, both are C-ranked journals in the current Australian journal ranking system, but were selected because of their rating as $A^{*}$ journals and ranking at first and second positions in a recent international survey (Friedman et al. 2008). While I acknowledge that a similar audit of other scholarly journals may demonstrate different gender distribution ratios than those evidenced here, other reasons for this choice were to delimit the audit as a succinct and credible example using journals originating in different continents and to which I had access, and to incorporate international journals of high standing and longevity in Design, broadly defined to include architecture, engineering and various sub-fields, such as graphic, interior and industrial design. 
Here, I acknowledge, but do not engage in, the body of work in biometrics and citation analysis, such as Tight's (2008) map of the citation practices and development of 'tribes' in adult education.

The audit of the publication histories of these two journals was conducted by counting editorials and articles comprising more than three pages, and organizing them by gender into categories of single and joint author. Where I could not identify gender, I omitted those articles and authors (11 per cent of articles, 14 per cent of authors), and where authors wrote more than one article in the same issue, they were counted as separate authors.

Design Studies is published in the United Kingdom (1979-2009), Design Issues is published in the United States (1984-2009), and both are available online. The audit accounted for 1,796 authors and 1,315 articles, of which 793 articles were written by single authors and 522 articles were written collaboratively in groups of two or more (1,003 authors).

The results were strikingly similar for both journals (see Table 1). While this snapshot of gender distribution in publication supports my argument, the following analysis explores the complexity and contradictions of the journals as gendered spaces that these statistics elide. Specifically, I discuss the implications for women and for Design scholarship through the framework of Foucault's 'microphysics of power' (cited in Threadgold 1997: 27) that operates within scholarly publication technologies (practices) to discipline bodies and speech. In scholarly journals, discipline is maintained in practice by subjecting individuals to, and directing them in, 'commentary', and in turn these individuals act as 
'carriers of practice' (Green 2009: 47), maintaining discipline through peer review and citation.

Table 1: Audit of gender distribution in publication, 'M' = men, ' $\mathrm{F}$ ' = women.

Comment [j20]: Please provide significance for the shaded areas in Table 1.

\begin{tabular}{|c|c|c|c|c|c|c|c|}
\hline & Design studies & M & F (per & Design issues & M & $\mathbf{F}(\mathbf{f}$ & $\begin{array}{l}\text { Comment [OU21]: No significance, } \\
\text { just a design element to separate the } \\
\text { information for clearer reading. I have } \\
\text { deleted the shading. }\end{array}$ \\
\hline & & $\begin{array}{l}\text { (per } \\
\text { cent) }\end{array}$ & cent) & & $\begin{array}{l}\text { (per } \\
\text { cent) }\end{array}$ & cent & \\
\hline \multirow{2}{*}{$\begin{array}{l}\text { Publication } \\
\text { history }\end{array}$} & Single author & 84 & 16 & Single author & 774 & 23 & Formatted Table \\
\hline & Joint author & 81 & 19 & Joint author & 68 & 32 & \\
\hline \multirow[t]{2}{*}{ 1979-1989 } & Single author & 89 & 11 & & & & \\
\hline & Joint author & 90 & 10 & & & & \\
\hline \multirow[t]{2}{*}{ 1984-1994 } & Single author & 85 & 15 & Single author & 85 & 15 & Formatted Table \\
\hline & Joint author & 88 & 12 & Joint author & 75 & 25 & \\
\hline \multirow[t]{2}{*}{ 1999-2009 } & Single author & 74 & 26 & Single author & 74 & 26 & \\
\hline & Joint author & 77 & 23 & Joint author & 61 & 39 & \\
\hline
\end{tabular}

Structured by Green's-Bourdieu's (Polkinghorne cited in Green 2009: 46) features of practice, I examine first the gender distribution of publications in each journal in different historical periods [time and space]; second the gender distribution of authorship and editorialship [tacit understanding (of how practice works)]; and third the implications of 
Foucault's 'commentary' around citation and 'esteem' as defined in the ERA Indicator

Descriptors (Australian Research Council 2008a, 2008b) [purposeful and strategic].

Comment [j22]: Please specify is it Australian Research Council (2008a) or Australian Research Council (2008b) here as per reference list.

Comment [OU23]: Confirmed 2008a

Time and space

The table presents an empirical account of the gender distribution of publication in the two journals. As expected, distribution is overwhelmingly and consistently gendered in both journals, in the first ten years of publication for each journal, in the last ten years, and across the publication histories of both journals. While this inequity supports my first argument, the broader implications will become evident in the following discussion.

In terms of authorship, statistically men are far more likely than women to be published in these journals (82 per cent in Design Studies and 75 per cent in Design Issues). Men are also much more likely to be published as single authors than women (84 per cent in Design Studies and 77 per cent in Design Issues). Articles co-authored by men are published more often than those by women (81 per cent in Design Studies and 68 per cent in Design Issues), and generally involve more authors per article than those co-authored by women. The implications at the institutional level are that in a joint-author publication, for each author located in a different university, each university is awarded the same credit, equal in value to a single-author article. This means that, statistically, coauthored articles written by individuals located in different universities attract higher status and more research funding for each institution, while increasing the measurable research output, profile and esteem of each academic. In turn, this favourably positions 
them for promotion to higher academic positions, potential appointment to editorial positions, increased esteem, and so on.

Interestingly, the ratio of single-author to joint-author publication in Design Issues is 70:30, while it is the inverse for Design Studies, at 68:32. This suggests that co-authored articles are more likely to be published in Design Studies, while single-authored articles are more likely to be published in Design Issues.

Publication by female authors has increased overall from 10 per cent in Design Studies' first ten years (1979-1989) to around 30 per cent in each journal in the last ten years (1999-2009). This suggests that women are now more likely to be published in these journals than previously, yet the level of representation does not reflect the increasing proportion of women in academic positions in Design. ${ }^{3}$ As academic level is an indicator of 'authoritative status' in citation analysis systems such as the ERA, these statistics highlight an inherent gender bias, as women remain under-represented at senior academic levels in Design, as in universities more generally (Tessens 2008).

In terms of editorials, Design Studies has published 58 editorials in 143 issues, of which 53 were authored by men and five by women (1993, 2006, twice in 2008, 2009). In 2008, and for the first time, two editorials were published in one issue, authored by a man and a woman. This appears to represent a seismic change in the gendered editorial practices of this journal, although a look at current editorial positions suggests otherwise. Design Issues has published 64 editorials in 73 issues, most of which were jointly authored by four or five of its male editors. Across its publication history, only three guest editors have been women $(2003,2005)$. 


\section{Tacit understanding (of how practice works)}

A scan of the editorial boards and committees of both journals tells an interesting story about the conditions under which Design is written. Across both journals, women's representation on editorial boards, editorial committees and advisory committees totals only nine of 61 positions (13 per cent). Design Studies has one male Editor-in-chief, one female and two male Associate Editors, and of the 26 members of the International Editorial Board, only five are women. Design Issues has a four-member, all-male editorial panel, and of its current editorial board and advisory board membership, only four of the 34 members are women. These figures suggest that highly regarded, influential (most often cited) men occupy editorial positions, and thus influence the focus, content and authorship of every issue of these highly ranked journals.

Participation in bounded, gendered journal spaces requires tacit understanding of how practice works through complex rule-governed, but contradictory, technologies.

Submission procedures regulate authors' compliance with article format and structure, word count, referencing style and deadlines, while peer-review and citation processes police and regulate entry to, and circulation through, these spaces. Yet these practices are predicated entirely on the judgment and continuing influence of highly placed individuals, most of whom are men. As speaking subjects, many of these men are also likely to have been involved in establishing the space, and continue to shape the space.

Writing authored by men consistently dominates both journals, making men's writing far more likely than women's to be cited in subsequent articles. As cited authors, men are more likely to become editors and senior academics, making them more likely to engage 
in peer-review and decision-making processes about who and what to publish, and where and when, but more importantly, who and what not to publish. This is how Foucault's ‘commentary’ operates (as practice).

\section{Purposeful and strategic}

Research funding under the ERA is partly determined by a volume and activity analysis that measures the profile of researchers in universities by academic level and headcount. Higher levels attract more institutional funding, which in turn impacts individuals' capacities for strategic interaction in the field in multiple ways, such as choices available, decision-making, career, promotion, remuneration, capacity to attract funding, prestige, authority and invitations to editorial boards. This is how gender plays out and is reproduced in the discipline-formation and field-building practices that constitute the

field of Design scholarship, and also constitute how fonstitute-women and men are reproduced as gendered subjects in the field. part 'and also...the field' is unclear. Please

While gender issues are not new to Design writing, as attested by the brief review of earlier 'women and Design' literatures that follows, I argue that new and different kinds of feminist-informed writing are required to disrupt the contemporary gendered spaces of scholarly journal writing in Design.

\section{On writing: feminism and Design}

The ‘first wave of ‘women and Design' literature’ (Attfield 2003: 77) began internationally in the late 1970s and early 1980s with the publication of several books and 
articles in scholarly journals of architecture, and feminist art and Design. ${ }^{4}$ The aim of these writers was to draw attention to and explain the lack of visibility of women in Design histories, practices and knowledges, and to challenge sex-based assumptions about women and Design. Drawing on feminist debates in other disciplines such as art, history and geography, the political goal was equality for women as designers and consumers of Design.

This 'first wave' continued until the early 1990s, its demise cooinciding I suggest, with the 'identity crisis' in feminism, perceived by some to be brought on in part by an antifeminist ‘backlash’ (Faludi 1992) and postmodernism (Buckley 1999: 110). Postmodernist theory, Buckley argues, poses a threat to feminism because it shifts the focus from 'women' to 'gender' (which includes masculinities as well as femininities), in the relations between power and knowledge.

Further, the relationship between the 'f-word' (Lupton 2000) and women in Design is complex and problematic. While women in Design commonly experience the issues feminism has politicized, few are actively involved in the feminist movement (Attfield Comment [u26]: Please cofinge
change made to this sentence.

Comment [OU27]: Change accepted 2003: 79). Feminist theory is also perceived to be too militant and/or too far removed from women's daily struggles in which they try 'to assert themselves and survive in a male-dominated profession'. While recognizing that these contradictions are not easily resolved, Attfield suggests that despite its threat, postmodernist theory offers a promising opportunity for women to 'rewrite discourses [...] from a political critique of the social positioning of women [...] rather than a vague thematics of "doing something”" (Morris cited in Attfield 2003: 81). The notion of feminism as 'critique' is discussed next. 
Since the early 1990s, feminist-informed writing has appeared sporadically in scholarly journals in art and Design. ${ }^{5}$ However, while some of this writing functions as 'critique', many writers do not explicitly identify as feminist, instead 'celebrating' women and their achievements. Here, the focus is on 'naming' women and restoring them to Design histories from which they have been excluded. Feminism problematizes such 'naming' (Riley 1988), partly because it restores a few women, as 'notable exceptions', to Design histories, and partly because it functions to categorize 'woman' with little regard to the cultural and social differences amongst women (Jones 1997: 262).

While naming 'women' is an important, yet problematic, political issue for feminism, the naming of 'Design, ${ }^{6}$ in an emergent discipline represents a further complication for feminist writers. This is particularly evident in recent debates about what counts as academic rigour (see for example, Wood 20001998) in a new professional scholarly field. Gorman (2001) problematizes the position Buckley (1986) takes in her seminal text, which is to expand the definition of Design to include craft so that more women can be restored to Design histories. Gorman (2001: 76, 86, 87) convincingly argues that attempts to rewrite histories in ways to include women are unhelpful for understanding 'the ubiquity and persistence of gender bias in the past'. Rather, the challenge for feminist Design writers is to be 'taken seriously by non-feminists and non-Design historians', who she calls the 'unconverted'. To achieve this, what is required is a reconsideration of language and 'a more rigorous and theoretically savvy form of rhetoric [to] address and sway an audience wider than themselves'. Such is my intention in this article.

Of particular interest for my discussion of citation practices earlier in this article is that beyond the network of 'women Design writers' who identify as feminist, this literature is 
generally not cited elsewhere. This reduces the possibility for feminist thinking to circulate in 'unconverted' Design audiences, and 'to challenge existing hierarchies of knowledge' (Lee and Poynton 2000: 1). Together, the reluctance of women to openly take up feminist writing positions in Design and the lack of citation in broader Design literatures of the few that do operate to maintain and (re)produce Design scholarship as gendered practice.

In brief, and to support the second argument in this article, I suggest that a contemporary progression from previous 'women and Design' literatures is required to move discussion beyond 'critique' and 'rendering women visible', to that which might productively disrupt the 'ubiquity and persistence of gender bias' (Gorman 2001: 86) in scholarly publication practices in Design. I argue that new questions must be raised and spaces opened for further study and different kinds of feminist-informed writing to make sense of and change how women and men position themselves, and also change how Design scholarship is practiced in the bounded spaces of scholarly journals.

\section{Where to from here?}

I have argued in this article for an examination of gender as it currently operates in the scholarly practices of new professional fields such as Design. I have explored the idea of scholarship as practice to make explicit the complex social, cultural and political dimensions of gender and publication in the space of scholarly Design journals that require mediation. In theorizing Design scholarship in this way, I am working against common conceptualizations in Design research that equate 'practice' with 'designing', to 
create a space that has the potential to constructively disrupt and reconceptualize the problematic relations amongst women, men, scholarship, Design and writing.

The audit I have presented in this article illustrates the gender distribution in publication of two Design journals in a reasonably straightforward way. It demonstrates that, statistically, men are far more likely to be published, and published as single authors, than women, while articles co-authored by men are published more often and generally involve more authors per article than those co-authored by women. Further, the majority of editorial positions in these journals are occupied by men, who are also more likely to have contributed to their establishment. But more telling than these statistics is the multiple and complex ways that the practices of peer review and citation operate to regulate and discipline bodies and texts within the gendered space of scholarly Design journals, such as the two examined here.

This audit is not without its limitations, and it is important to acknowledge the probability that other scholarly Design journals and journals in related and more established fields such as architecture and art and Design education will have different (higher or lower) representations of female authors and editors and also higher (or lower) journal rankings. It is possible to argue that journals reflecting traditional disciplinary gender divisions in Design, for example those considered 'feminine' such as interior design, or 'masculine' such as architecture, reinforce and reproduce rather than disrupt the operation of gender in scholarship practices, while journals representing fields with close associations with feminism such as Art History address 'the converted'. 
Here, my intention is not to make universalizing claims, nor to exacerbate the already problematic relations amongst women, Design and feminism. Rather, it is more productive for the field to account for and theorize issues of gender through empirical research, and, following Gorman (2001: 87), more productive for writers to employ feminist-informed, 'theoretically-savvy rhetoric' to sway 'the uncoverted' to attend to the ‘ubiquity and persistence of gender bias’ in Design scholarship practices.

In the current audit conditions of the performative university in which academics are increasingly required to research, write and publish in high-ranking scholarly journals, the contemporary need to attend to issues of gender, and attend to the relationship between practice and representation in emergent professional fields such as Design, will only increase. This is particularly so for those professions in which a gender bias persists, such as Nursing and Occupational Therapy.

My explorations of feminist-informed writing, different to those of critique or celebration, are presented in this spirit to both raise awareness and open space so that an ethical and productive way forward for professional fields may be written into practice, by women and by men.

I would also argue that there is an essential role to be played by journal editors and senior academics, particularly those engaged in peer-review processes. My informal discussions with women in these positions suggest that while they may have experienced gender discrimination personally, they may not recognize the depth and complexity of the operation of gender in the publication practices in which they have become acculturated and which they reproduce as 'carriers of practice' (Green 2009: 47). Other discussions 
with women in more junior academic positions suggest that many struggle to negotiate such practices, often withdrawing from scholarly journal writing, or actively seeking alternatives, to the detriment of their career progression and capacity to attract research funding. While this is clearly problematic for female academics, in a professional field in the early stages of discipline-formation such as Design, it is of critical importance.

References

Attfield, J. (2003), 'Review Article: What Does History Have to Do With it? Feminism and Design History', Journal of Design History, 16:1, pp. 77-87.

Australian Research Council (2008a), ‘ERA Indicator Descriptors, Canberra:

Commonwealth of Australia', http://www.arc.gov.au/pdf/ERA_Indicator_Descriptors.pdf. Accessed 17 September 2009.

Australian Research Council (2008b), 'ERA Indicator Principles, Canberra: Commonwealth of Australia', http://www.arc.gov.au/pdf/ERA_Indicator_Principles.pdf. Accessed 17 September 2009. 
Bower, K., Clerke, T. and Lee, A. (2009), 'Endangered Practices: Writing Feminist Research', in J. Higgs, D. Horsfall and S. Grace (eds), Writing Qualitative Research on Practice, Rotterdam: Sense Publishers.

Buckley, C. (1986), 'Made in Patriarchy: Toward a Feminist Analysis of Women and Design', Design Issues, 3:1, pp. 3-14.

Buckley, C. (1999), 'Made in Patriarchy: Theories of Women and Design - A Reworking', in J. Rothschild (ed.), Design and Feminism: Re-visioning Spaces, Places and Everyday Things, New Brunswick: Rutgers University Press.

Faludi, S. (1992), Backlash: The Undeclared War Against American Women, London: Chatto \& Windus.

Friedman, K., Barron, D., Ferlazzo, S., Ivanka, T., Melles, G. and Yuille, J. (2008), Design Research Journal Ranking Study_-:Preliminary Results, Melbourne: Swinburne University and RMITof Technology Faculty of Design. 
Gorman, C. (2001), 'Reshaping and Rethinking: Recent Feminist Scholarship on Design and Designers’, Design Issues, 17:4, pp. 77-88.

Green, B. (2009), Understanding and Researching Professional Practice, Rotterdam: Sense Publishers.

Jones, A. (1997), 'Teaching Post-structuralist Feminist Theory in Education: Student resistances', Gender and Education, 9:3, pp. 261-9.

Lee, A. and Poynton, C. (2000), Culture \& Text, St Leonards: Allen and Unwin.

Lupton, E. (2000), ‘Women Graphic Designers’, Typotheque, http://www.typotheque.com/articles/women_graphic_designers. Accessed 20 September 2009.

McQuiston, L. (1988), Women in Design: A Contemporary View, London: Trefoil. 
Riley, D. (1988), 'Am I that Name?': Feminism and the Category of Women in History, Minnesota: University of Minnesota Press.

Tessens, L. (2008), ‘A review of current practices in women-only staff development programmes at Australian universities’, in Higher Education Research and Development Society of Australasia, Inc., Engaging Communities, Proceedings of the 31st HERDSA Annual Conference, Rotorua, Rotorua, New Zealand, 1-4 July, Milperra: Higher Education Research and Development Society of Australasia, Inc.

Threadgold, T. (1997), Feminist Poetics. Poiesis, Performance, Histories, London: Routledge.

Tight, M. (2008), ‘Higher Education Research as Tribe, Territory and/or Community: A Co-citation Analysis', Higher Education, 55:5, pp. 593-605.

Wood, J. (Z0001998), 'The Culture of Academic Rigour: Does Design Research Really Need It?', The Design Journal, 3:1, pp. 44-57. 


\section{Contributor details}

Teena Clerke has worked as a Graphic Designer since 1987, focusing on community cultural development and Design for social change. She has participated in solo and group art exhibitions, and has work represented in private collections in Australia and internationally. Clerke has lectured in Design since 1994, currently lectures in Design at the University of Sydney, and is a doctoral intern at the University of Technology, Sydney, lecturing in adult education. Her doctoral research investigates the experiences of women Design academics, and she has published in the areas of Design education, doctoral education, feminist qualitative research writing and cultural studies.

Contact:

Teena Clerke, Doctoral Intern, Education, Faculty of Arts and Social Sciences University of Technology, Sydney, P.O. Box 1090 Strawberry Hills NSW 2010 Australia

E-mail: teena.clerke@uts.edu.au 
${ }^{1}$ Australia is currently restructuring its scholarly journal rankings policy, Excellence in Research for Australia (ERA) - see Australian Research Council (2008a, b) $)$, ERA Indicator Descriptors, Commonwealth of Australia http://www.arc.gov.au/era/indicators.htm. Please specify is it Australian Research Gouncil (2008a) or Australian Research Council (2008b) here as per reference list.]

${ }^{2}$ A recent online list post by one of the authors of the 2008 study provides further information: 'The Australian Research Council (ARC) is aware of the new ranking proposal from the Australian Deans of the Built Environment and Design (ADBED). [...] For several methodological and practical reasons, the final ADBED list does not mirror the 2008 study, but it does two important things. First, it offers a responsible view from the design discipline, incorporating both Australian and worldwide opinion. While the 2008 study did this to a great degree, it was quick and dirty. We intended it to spark dialogue and reflection for a better national,... and it did what we intended. (AQ: Please eonfirm whether there is text missing after 'national' in this quote as the meaning is unclear.).We had the added benefit of helping designers and design research scholars in other nations with similar projects for university or national queries. Second, ADBED is the high-level voice of the field, and that means the ADBED list has a role in the national debate that no single university research project can have', (Friedman, K., https://www.jiscmail.ac.uk/cgi-bin/webadmin?A2=ind1001\&L=PHDDESIGN\&D=0\&P=36919http://jiscmail.ac.uk/cgi-bin/webadmin?IIST=PHD-DESIGN. Accessed 13 January 2010.

${ }^{3}$ For example, the Equity and Diversity Unit at the University in Technology, Sydney reported that women's representation in academic positions in the Faculty of Design Architecture and Building in 2008 was around 37 per cent $\%$, slightly lower than the University of Technology, Sydney average of 40 per cent $\%$, and less than the 50 per cent $\%$ government benchmark. However, women comprise 50 per cent $\%$ of academics in Visual Communication. (AQ: Please provide the expansion of 'UTS')

${ }^{4}$ See for example, Moore Trescott ([1976]/-1979; $)$ _Heresies: A Feminist Publication on Art \& Politics first published in 1976; ; Hayden $(1982 ;)$, Rothschild $(1982 \div)$, Kirkham (1983; ), Anscombe (1984;), and Parker (1984).

${ }^{5}$ See for example, Seddon (1993;), Buckley (1994; ), Scotford (1994;), Worden \& and Seddon (1995;), Clegg \& and Mayfield (1999;), Gorman (2001;), Hagmann $(2005 ;)$ and Sadowska (2006).

${ }^{6}$ How design can be named and practiced, and who can name themselves as 'designer' and why, constitutes an ongoing topic of scholarly debate - see for example, Ph.D. Design Research List, http://jiscmail.ac.uk/cgi-bin/webadmin?LIST=PHD-DESIGN.
Formatted: Font: Times New Roman $12 \mathrm{pt}$

Formatted: Font: Times New Roman $12 \mathrm{pt}$

Formatted: Font: Times New Roman $12 \mathrm{pt}$

Formatted: Font: Times New Roman, $12 \mathrm{pt}$

Formatted: Font: Times New Roman $12 \mathrm{pt}$

Formatted: Font: Times New Roman, $12 \mathrm{pt}$

Formatted: Font: Times New Roman $12 \mathrm{pt}$

Formatted: Font: Times New Roman, $12 \mathrm{pt}$

Formatted: Font: Times New Roman, $12 \mathrm{pt}$

Formatted: Font: Times New Roman, $12 \mathrm{pt}$

Formatted: Font: Times New Roman, $12 \mathrm{pt}$

Formatted: Font: Times New Roman, $12 \mathrm{pt}$

Formatted: Font: Times New Roman, $12 \mathrm{pt}$

Formatted: Font: Times New Roman, $12 \mathrm{pt}$

Formatted: Font: Times New Roman, $12 \mathrm{pt}$

Formatted: Font: Times New Roman, $12 \mathrm{pt}$

Formatted: Font: Times New Roman, $12 \mathrm{pt}$

Formatted: Font: Times New Roman, $12 \mathrm{pt}$

Formatted: Font: Times New Roman,

$12 \mathrm{pt}$

Formatted: Font: Times New Roman, $12 \mathrm{pt}$

Formatted: Font: Times New Roman, $12 \mathrm{pt}$

Formatted: Font: Times New Roman, $12 \mathrm{pt}$

Formatted: Font: Times New Roman, $12 \mathrm{pt}$ 